\title{
S'COOL Provides Research Opportunities and Current Data for Today's Technological Classroom
}

\author{
Carolyn J. Green \\ Science Applications International Corporation \\ One Enterprise Parkway, Suite 300 \\ Hampton, VA 23666-5845 \\ (757) 864-5698/tel. (757) 864-7996/fax \\ carolyn.j.green@larc.nasa.gov \\ Lin H. Chambers \\ National Aeronautics and Space Administration \\ Langley Research Center, Mail Code 420 \\ Hampton, VA 23681-2199 \\ Anne M. Racel \\ Computer Sciences Corporation \\ 3217 N. Armistead Ave. \\ Hampton, VA 23666
}

\section{INTRODUCTION}

NASA's Students' Cloud Observations On-Line (S'COOL) project, a hands-on educational project, was an innovative idea conceived by the scientists in the Radiation Sciences Branch at NASA Langley Research Center, Hampton, Virginia, in 1996. It came about after a local teacher expressed the idea that she wanted her students to be involved in real-life science. S'COOL supports NASA's Clouds and the Earth's Radiant Energy System (CERES) instrument, which was launched on the Tropical Rainforest Measuring Mission (TRMM) in November, 1997, as part of NASA's Earth Science Enterprise. With the S'COOL project students observe clouds and related weather conditions, compute data and note vital information while obtaining ground truth observations for the CERES instrument. The observations can then be used to help validate the CERES measurements, particularly detection of clear sky from space. In addition to meeting math, science and geography standards, students are engaged in using the computer to obtain, report and analyze current data, thus bringing modern technology into the realm of classroom, a paradigm that demands our attention.

\section{IMPLEMENTATION}

In 1997 the project, under the supervision of Principal Investigator Dr. Lin Chambers, was piloted with approximately thirty schools. At the time of this writing the project has grown to 229 participating sites, representing 19 countries on six continents. Students from 9 to 18 years old have been committing time and effort to supporting the research of the CERES team. S'COOL's most recent intensive month of observations occurred in
January, 1999. During the period between January 4 and 25 , our most recent month of intensive observations, NASA received 188 observations from the global pool of students.

In an effort to meet the high demand for technological application of current research the project actively engages students in a variety of computer tasks. Using links provided on the $\mathrm{S}^{\prime} \mathrm{COOL}$ website students are able to perform various functions, such as calculating satellite overpass times, converting various measurements to the required units and applying findings in suggested lab activities. Students are encouraged to download current data for study and analysis. Opportunity and instruction for using data in creating graphs, mapping activities and statistical application is provided at the website, where instructions lead them through sequential learning steps for computer usage to accomplish those tasks.

From its inception it was determined that this project should be as available as possible to any teacher in related fields. Science, math, geography and technology have been skillfully woven into the fabric of the S'COOL project. Even though great effort has been made to encourage participation by internet, schools are not prevented from participating because of lack of funds to support the technology. NASA provides the necessary materials for school participation.

In May 1998 S'COOL was selected for a joint NASA/CNES educational demonstration held in Paris, France. The cooperative effort occurred May 13 with a trans-Atlantic demonstration featuring US First Lady Hillary Clinton in Paris and NASA Administrator Dan Goldin in Washington, DC, and other dignitaries at these two sites as well as an additional site in Brooklyn, NY. The event demonstrated how students, who had previously made cloud observations at these three sites at the same 
time, shared their results by internet with their internationally paired classes. Observations were coordinated with the overpass of NOAA or Meteosat satellites, so that students could compare their findings with those of the satellite. An Ichat system allowed students to exchange questions and answers about each others' observations.

For that student or teacher who lacks confidence in the area of meteorology help is near. Through numerous links on the S'COOL website a student or instructor can find cloud identification, explanation of terminology and step by step directions for using their computers to upload and download data and to otherwise process it. A quarterly newsletter keeps participants informed of new developments and introduces them to some of the experts in the field. Questions submitted to the S'COOL team are answered by members of the S'COOL and CERES team.

\section{SUMMARY}

An article titled, "One Small Step for NASA," grabbed the headlines in Spartanburg, SC, USA, recently as students under the direction of their instructor Dr. Donovan, made observations for the S'COOL project. The project extended to learning about satellites and weather. Teacher Ms. Westmoreland acknowledged that the students noticed things that previously they had not.

"Once you do something like this you look at clouds in a different way," student Robert Few said.

"It made me more interested in science, in the weather ...," said Bret Hayes. "It made it more interesting because we've been working with NASA," Chuck Watson added. One of our teachers, Margaret Holtschlag recently sent us the following comment," I think starting the day with the sky observation has been the most dramatic thing I've added to the children's learning experience. When I hear that they are observing at night, on their way to school, other times besides our lesson time, I know that it's meaningful and important to them." We hope students will continue to experience benefits like those mentioned by the above students and Ms. Holtschlag as the project continues through the next decade.

Students around the world have demonstrated great commitment and enthusiasm for S'COOL. Some classes and even individual students have continued their observations while vacationing. This has enabled S'COOL to obtain ground truth data from some rather remote areas, such as the French Alps, which otherwise might not have been available. Long distance learning projects, like S'COOL, benefit both the student in the classroom and lend vital support to important earth monitoring systems such as CERES.

The S'COOL project is an ongoing endeavor. Interested teachers are directed to the contact information section of this paper. Registration information can be obtained in the same manner.

\section{REFERENCES}

[1]. Chambers, Lin H., David F. Young, Carolyn J. Green, Martial P. Haeffelin, and Anne M. Racel, The CERES S'COOL Project: Operational but not Routine, Proceedings of the Eighth Symposium on Education, American Meteorological Society, Dallas, TX, January, 1999, pp. 176-179.

[2]. Green, Carolyn J. Green, Lin H. Chambers, Project S'COOL", Proceedings of the International Geoscience and Remote Sensing Symposium, Seattle, WA, July, 1998.

[3]. Chambers, Lin H., D. F. Young, and Anne.M. Racel, "The CERES S'COOL Project: Development and Operational Phases", Proceedings of the Seventh Symposium on Education, American Meteorological Society, pp. 90-93, January, 1998.

\section{CONTACT INFORMATION}

E-mail: scool@larc.nasa.gov

Mail: S'COOL Project Mail Stop 420

NASA Langley Research Center

Hampton, VA 23681-2199

Fax: $\quad 1$ (705) 864-7996

Phone: 1 (705) 864- 5682

URL: <http://asd-www.larc.nasa.gov/SCOOL/> 